LENTERA PENDIDIKAN, EDISI X, NO. 2, DESEMBER 2007 (173-184)

\title{
PENGARUH MODEL PEMBELAJARAN SYNECTICS DIPADU MIND MAPS TERHADAP KEMAMPUAN BERPIKIR KREATIF, SIKAP KREATIF, DAN PENGUASAAN MATERI BIOLOGI
}

\author{
Oleh: Muh. Khalifah Mustami
}

\begin{abstract}
One of the important tasks in teaching is assisting students to think. Synectics Model matched with Mind Maps are viewed necessary to be applied in the instruction in order to achieve the target.The research is an experiment research with pre-test posttest control group design. The results of analyses indicate that: (1) there is significance difference with the mean score of creative think ability, creative attitude, and mastery of biology materials due to difference of instruction model used, (2) there is no significant difference of mean score of creative attitude among the students who belong to the high and low achievement. (3) there is no interactional effect between the instructional model used with the students entry behavior towards creative thinking ability, creative attitude, and mastery of biology materials.
\end{abstract}

KEYWORDS: Synectics, mind maps, berpikir kreatif, sikap kreatif

DUNIA pendidikan dewasa ini dihadapkan pada suatu tantangan yaitu era pengetahuan (knowledge era). Era ini ditandai dengan perkembangan teknologi yang sangat pesat, penuh ketidakpastian, dan dilema. Menurut Handy, sebagaimana dikutip oleh Gibson, era tersebut merupakan era modal intelektual (intellectual capital). ${ }^{1}$ Oleh karena itu, tujuan pendidikan dan pengajaran hendaknya bermuara pada pemenuhan keterampilan intelektual siswa agar kelak dapat berasimilasi dengan era pengetahuan. Untuk mewujudkan tujuan tersebut, tampaknya perlu diperhatikan apa yang dikemukakan Raths et. al. bahwa perlu mewujudkan tugas yang terpenting dalam mengajar yaitu membantu siswa berpikir. ${ }^{2}$

Salah satu keterampilan intelektual yang perlu diberikan kepada siswa adalah keterampilan mengembangkan daya cipta atau pemikiran kreatif agar ia menjadi individu yang kreatif. ${ }^{3}$ Oleh karena itu, hendaknya semua guru mata pelajaran berusaha atau bertujuan untuk mengembangkan kemampuan kreatif siswa sehingga mereka bergerak ke arah "aktualisasi diri" serta kesehatan mental yang lebih baik. ${ }^{4}$ Dengan kata lain pemberdayaan siswa agar menjadi kreatif, misalnya dalam hal berpikir 
kreatif dan kepemilikan kesehatan mental berupa sikap kreatif yang baik perlu diwujudkan dan dijadikan tujuan dalam kegiatan pembelajaran. Begitu pentingnya berpikir kreatif dalam kegiatan pembelajaran, Splitter menjelaskan bahwa berpikir kreatif dapat mempersiapkan siswa berpikir dalam berbagai disiplin ilmu, menuju pemenuhan akan kebutuhan intelektualnya dan mengembangkannya sebagai individu berpotensi. Lebih lanjut dijelaskan bahwa dalam proses pembelajaran lebih melibatkan siswa sebagai pemikir daripada pengumpul pengetahuan. ${ }^{5}$ Sementara, dalam praktik pendidikan dan pembelajaran kita, pengembangan berpikir kreatif siswa kurang dijadikan sebagai tujuan pembelajaran. Pembelajaran di sekolah-sekolah telah dikebiri menjadi perolehan informasi dengan sistem tagihan yang mengutamakan hasil belajar jangka pendek dan hanya dipandang dalam satu dimensi yaitu dimensi produk saja. Sementara, pembentukan kemampuan-kemampuan yang memerlukan jangka waktu lebih lama serta merupakan misi lintas mata pelajaran, seperti kemampuan berpikir, kemampuan menyelesaikan masalah dan memandang pengalaman belajar sebagai suatu sistem pola berpikir yang logis dan kreatif, masih cukup jauh tertinggal penanganannya. ${ }^{6}$ Sebagai bukti terhadap hal dimaksud lulusan sekolah-sekolah kita masih terlalu pasif, menunggu, dan masih suka mencari kerja ketimbang menciptakan pekerjaan. Karena itu, menurut Ciputra pendidikan dan pembelajaran di negeri ini, harus mengajarkan ilmu kehidupan berupa kreativitas. Sebab, untuk hidup orang harus kreatif. ${ }^{7}$

Berdasarkan fenomena dan hasil pembelajaran kita seperti dikemukakan di atas, saatnya pendidikan dan pembelajaran di negeri ini mengembangkan pembelajaran kreatif. Pembelajaran kreatif adalah pembelajaran yang bertujuan meningkatkan perilaku kreatif, menggerakkan potensi kreativitas siswa seperti berpikir kreatif, dan menimbulkan berbagai getaran penemuan terhadap hal-hal yang sebelumnya belum diketahui; belum dikenal atau belum dipahaminya. Sebagai pengalaman belajar yang menyenangkan, pada pembelajaran kreatif siswa terlibat secara aktif mendalami bahan yang dipelajari dengan menggunakan proses berpikir kreatif. Menurut Torrance pembelajaran kreatif adalah pembelajaran untuk mengembangkan kreativitas siswa. ${ }^{8}$ Pada pembelajaran kreatif ditandai adanya hubungan kreatif antara guru dengan siswa dan menggunakan model-model pembelajaran yang dapat mengembangkan daya kreatif. Hubungan kreatif guru dan siswa dalam pembelajaran kreatif, oleh guru diwujudkan dalam bentuk seperti: menghargai pertanyaan dan ide-ide siswa, berusaha memahami apa yang dipikirkan siswa, mendorong untuk berpikir lebih mendalam dan lebih terbuka. Jadi, dapat disimpulkan bahwa 
pembelajaran kreatif adalah pembelajaran yang bertujuan untuk mengembangkan kreativitas, yang penerapannya membu-tuhkan model dan sarana pembelajaran yang tepat, salah satunya adalah model synectics dan sarana berupa mind maps.

Masalahnya adalah guru di sekolah "merasa" sangat sibuk dan tidak memiliki waktu yang cukup untuk merancang pembelajaran kreatif. Mereka lebih suka memanfaatkan disain atau skenario pembelajaran yang sudah dikembangkan dan siap dioperasionalkan. Berdasarkan hal tersebut penulis mengembangkan model pembelajaran kreatif dengan harapan pebelajar dapat memiliki kompetensi kreativitas sebagai bekal kehidupan.

\section{METODE}

Penelitian ini merupakan penelitian quasi-experiment dengan pretestposttest control group desain..$^{9}$ Sampelnya adalah siswa SMP Kota Makassar tahun pelajaran 2006/2007 yang ditarik secara random dari sekolah yang memiliki grade menengah. Variabel terikat yang diukur adalah kemampuan berpikir kreatif, sikap kreatif, dan penguasaan materi biologi. Instrumen yang digunakan antara lain: (1) tes kemampuan berpikir kreatif yang dikembangkan sendiri oleh penulis, disesuaikan dengan materi ajar dengan indikator berupa fluency, flexibility, originality, dan elaboration dalam mengemukakan gagasan-gagasan atau ide yang dibuat dalam 5 unit test. (2) angket skala sikap kreatif untuk mengetahui sikap kreatif. (3) soal pilihan ganda dan esai untuk mengetahui penguasaan materi biologi. Datadata yang diperoleh dianalisis dengan statistik infrensial berupa analisis kovariat (ancova).

\section{HASIL}

Berdasarkan hasil analisis data, maka dapat dikemukakan temuan penelitian berupa kemampuan berpikir kreatif, sikap kreatif, dan penguasaan materi biologi sebagai akibat dari perlakuan model pembelajaran yang digunakan sebagai berikut.

\section{Berpikir Kreatif}

Hasil analisis menunjukkan bahwa: (1) nilai F kelas perlakuan sebesar 133,229 dengan probabilitas 0,000 lebih kecil dari 0,05 yang berarti bahwa pengaruh model pembelajaran terhadap kemampuan berpikir kreatif adalah signifikan. (2) nilai $\mathrm{F}$ siswa yang berbeda kemampuan awalnya sebesar 3,603 dengan probabilitas 0,603 lebih besar dari 0,05 (signifikansi 5\%) yang berarti tidak ada perbedaan kemampuan berpikir kreatif pada siswa yang berbeda kemampuan awalnya. (3) nilai F interaksi 
antara model pembelajaran yang digunakan dengan kemampuan awal siswa sebesar 0,411 dengan probabilitas 0,524 lebih besar dari 0,05 (signifikansi 5\%) yang berarti bahwa tidak ada pengaruh interaksi antara model pembelajaran yang digunakan dengan kemampuan awal siswa terhadap kemampuan berpikir kreatif. (4) kategori kemampuan berpikir kreatif siswa yang berbeda kemampuan awal, setelah dibelajarkan dengan model pembelajaran synectics dipadu mind maps meningkat dari kategori sedang menjadi kategori tinggi.

\section{Sikap Kreatif}

Hasil analisis data menunjukkan bahwa: (1) nilai $\mathrm{F}$ kelas perlakuan sebesar 86,636 dengan probabilitas 0,000 lebih kecil dari 0,05 (signifikansi $5 \%)$ yang berarti bahwa pengaruh perlakuan model pembelajaran yang digunakan terhadap sikap kreatif adalah signifikan. (2) nilai F siswa yang berbeda kemampuan awalnya sebesar 0,022 dengan probabilitas 0,883 lebih besar dari 0,05 (signifikansi 5\%) yang berarti tidak ada perbedaan sikap kreatif antara siswa yang berbeda kemampuan awalnya. (3) nilai $\mathrm{F}$ interaksi antara model pembelajaran yang digunakan dengan kemampuan awal siswa sebesar 0,295 dengan probabilitas 0,589 lebih besar dari 0,05 (signifikansi 5\%) yang berarti bahwa tidak ada pengaruh interaksi antara model pembelajaran yang digunakan dengan kemampuan awal siswa terhadap sikap kreatif. (4) kategori sikap kreatif siswa setelah dibelajarkan dengan model pembelajaran synectics dipadu mind maps meningkat dari kategori kurang menjadi sedang untuk siswa yang berkemampuan awal rendah. Sedangkan untuk siswa berkemampuan tinggi kategori sikap kreatifnya tetap sedang setelah dibejarkan dengan model pembelajaran synectics dipadu mind maps.

\section{Penguasaan Materi Biologi}

Hasil analisis data menunjukkan bahwa: (1) nilai F kelas perlakuan sebesar 4,827 dengan probabilitas 0,032 lebih kecil dari 0,05 (signifikansi $5 \%$ ), ini berarti perbedaan penguasaan materi biologi karena perlakuan model pembelajaran yang digunakan adalah sisgnifikan. (2) nilai F siswa yang berbeda kemampuan awalnya sebesar 0,519 dengan probabilitas 0,474 lebih besar dari 0,05 (signifikansi 5\%) yang berarti tidak ada perbedaan penguasaan materi biologi pada siswa yang berbeda kemampuan awalnya. (3) nilai $\mathrm{F}$ interaksi antara model pembelajaran yang digunakan dengan kemampuan awal siswa sebesar 0,302 dengan probabilitas 0,585 lebih besar dari 0,05 (signifikansi 5\%), ini berarti tidak ada pengaruh interaksi antara model pembelajaran yang digunakan dengan kemampuan awal siswa 
terhadap penguasaan materi biologi. model pembelajaran. (4) kategori penguasaan materi biologi siswa setelah dibelajarkan dengan model pembelajaran synectics dipadu mind maps meningkat dari kategori sedang menjadi tinggi untuk siswa yang berbeda kemampuan awalnya.

\section{PEMBAHASAN}

Dengan maksud "mendudukkan" temuan penelitian dalam khasanah ilmu, maka dilakukan pembahasan sebagai berikut. Pembelajaran model synectics dipadu mind maps dapat mengembangkan kemampuan berpikir kreatif, sikap kreatif, dan penguasaan materi biologi siswa seperti temuan dalam penelitian ini sangat dimungkinkan. Alasannya adalah karena model synectics merupakan model pembelajaran yang memungkinkan terwujudnya tujuan pembelajaran kreatif. Model ini dikembangkan dari seperangkat anggapan dasar tentang psikologi kreativitas. Anggapan dasar itu oleh Gordon dituangkan dalam tiga asumsi dasar yang mendasari synectics, yaitu: (1) proses kreatif dapat dideskripsikan secara konkret, deskripsi ini dapat digunakan untuk mengembangkan metode pengajaran yang dapat mengembangkan kreativitas secara individual maupun kelompok, (2) penemuan kreatif dalam bidang seni dan bidang sains serupa, dan diperoleh melalui proses dasar intelektual yang sama, dan (3) proses kreatif individu serupa dengan proses kreatif dalam kelompok. Di samping itu Gordon juga menjelaskan bahwa komponen emosional jauh lebih penting dibandingkan intelektual pada awal proses kreatif. ${ }^{10}$

Joyce dan Weil serta Brownoski menjelaskan bahwa model synectics merupakan model pengembangan kreativitas untuk memecahkan masalah dengan melatih individu untuk bekerja sama mengatasi problem sehingga mampu meningkatkan produktivitas. ${ }^{11}$ Lebih spesifik Hudson menjelaskan bahwa pembelajaran model synectics merupakan aktivitas yang disusun dan digunakan para siswa sebagai cara untuk berpikir kreatif. ${ }^{12}$ Jika demikian halnya, maka synectics dapat dipahami sebagai seperangkat kreativitas (pemikiran kreatif) untuk menyatakan permasalahan dan pemecahannya.

Pembelajaran model synectics menekankan pada adanya kegiatan analogi dalam belajar, yang bermuara pada perolehan pemahaman baru dan lebih kompleks terhadap suatu konsep. ${ }^{13}$ Analogi sebagai cara kerja synectics dalam belajar, dapat didefinisikan sebagai aktivitas membuat perumpamaan-perumpamaan suatu hal (konsep baru) terhadap suatu hal lain (konsep yang sudah dipahami) berdasarkan persamaan-persamaan antara keduanya, untuk memperoleh pemahaman konsep yang lebih kompleks. ${ }^{14}$ Analogi sebagai cara berpikir, umumnya orang menggunakan perbandingan atau kontras. ${ }^{15}$ Dalam teori kebahasaan, Wahab menjelaskan 
analogi sebagai ungkapan kebahasaan, yang maknanya tidak dapat dijangkau secara langsung dari lambang, karena makna yang dimaksud terdapat pada prediksi kebahasaan itu. ${ }^{16}$

Melalui analogi maka terjadi suatu proses kreatif yang disadari, terbentuk jarak konseptual antara siswa dengan obyek, dan memungkinkan untuk berpikir kreatif. ${ }^{17}$ Dengan terbentuknya jarak konseptual maka secara emosional akan memberikan kebebasan struktur mental dan dapat mengarahkan ke dalam cara berpikir yang baru. Sejalan dengan hal tersebut, Amien menjelaskan bahwa kegiatan analogi dapat membantu melepaskan "ikatan struktural mental", yang melekat kuat dalam memandang suatu objek sehingga mendukung munculnya gagasan-gagasan yang kreatif. 18

Menurut Ramasami model synectics sangat membantu dalam menemukan dan menjelaskan konsep-konsep yang dipelajari. Pada saat siswa melakukan aktivitas synectics, maka proses pembelajaran menjadi aktif sebagai akibat dari usaha siswa mencari analogi yang sesuai untuk memahami topik. ${ }^{19}$ De Bono mengemukakan bahwa dengan kegiatan analogi, siswa dalam belajarnya tidak hanya belajar lebih banyak konsep, tetapi mereka menggunakannya sebagai suatu jenis kreativitas berpikir yang disebut "berpikir lateral".20 Sejalan dengan hal tersebut, Coom menjelaskan bahwa berpikir analogi dapat mengembangkan apresiasi kreatif siswa dan membantu perkembangan daya ciptanya. Lebih jauh dijelaskan bahwa berpikir analogi dapat memperluas pola pikir kreatifnya dengan melakukan kajian secara interdisipliner. ${ }^{21}$

Aktivitas analogi sebagai cara kerja synectics sesungguhnya juga merupakan bentuk pengorganisasian pengetahuan. Siswa dalam memahami konsep yang dipelajari melalui aktivitas analogi, senantiasa menghubungkan konsep-konsep yang sudah terorganisir dan menjadi miliknya dengan konsep yang sedang dipelajari. Jika, dikaitkan dengan pengorganisasian kognitif, maka aktivitas analogi sesuai dengan teori elaborasi kognitif.

Teori elaborasi didukung oleh dua bidang kajian psikologi kognitif, yaitu: (1) teori tentang struktur representasi kognitif. Struktur kognitif didefinisikan sebagai struktur organisasional yang ada dalam ingatan/ skema seseorang yang mengintegrasikan unsur-unsur yang terpisah-pisah ke dalam suatu unit konseptual; (2) proses ingatan (memory). Proses ingatan adalah mekanisme penyandian, penyimpanan, dan pengungkapan kembali apa yang telah disimpan dalam ingatan. ${ }^{22}$ Jadi, dapat disimpulkan bahwa elaborasi merupakan suatu proses penstrukturan kembali kognitif karena masuknya informasi baru ke dalam ingatan. 
Menurut Gunter, prosedur synectics awalnya digunakan untuk keperluan mengembangkan kreativitas kelompok dalam organisasi-organisasi industri. Individu dilatih agar mampu bekerja sama dengan yang lainnya dalam mengatasi masalah dan mengembangkan produksi.23 Dalam perspektif pembelajaran Glynn et. al. menjelaskan bahwa synectics telah memainkan peran penting dalam memberikan penjelasan secara ilmiah, pengertian yang mendalam, penemuan, dan kreativitas. Lebih jauh dijelaskan bahwa penggunaan analogi dalam pembelajaran harus berhatihati karena kalau salah akan merugikan siswa. ${ }^{24}$ Ini berarti bahwa synectics sebagai model pembelajaran memerlukan pembiasaan dan latihan dalam penggunaannya, baik oleh siswa maupun guru.

Membelajarkan siswa dengan model synectics tidaklah mudah. Oleh karena itu, perlu prasarana yang tepat untuk memperlancar aktivitas analogi sebagai kerja synectics. Setelah dilakukan analisis kritis terhadap beberapa prasarana belajar yang memungkinkan untuk dipadu dengan model synectics, penulis memilih mind maps. Ternyata temuan penelitian ini terkait dengan hal tersebut menunjukkan hasil yang positif.

Bagaimana kemudian mind maps memberikan efek positif terhadap pengembangan kemapuan berpikir kreatif, pembentukan sikap kreatif, dan peningkatan penguasaan materi pelajaran dapat dikemukakan seperti berikut. Pemanfaatan mind maps sebagai prasarana pembelajaran, dalam hal ini untuk memperlancar aktivitas analogi sangat dimungkinkan. Oleh karena, melalui mind maps siswa dapat memetakan seluruh pengetahuannya melalui pembentukan cabang-cabang yang berhubungan dengan topik yang sedang dipelajari. Menurut Buzan, mind maps merupakan alat berpikir yang mampu mendorong kerja otak untuk mengembangkan asosiasi antar gagasan dan merupakan manifestasi visual tentang cara otak dalam berpikir. ${ }^{25}$ Berdasarkan penjelasan tersebut, dapat dikemukakan bahwa mind maps dapat memperlancar aktivitas analogi dalam synectics. Oleh karena, keduanya memiliki cara kerja yang relatif sama yaitu sama-sama melakukan asosiasi-asosiasi gagasan.

Mind maps sebagai peta-jalan pembelajaran dapat membantu dalam mengembangkan potensi berpikir secara kreatif. Melalui mind maps orang mampu memfokuskan perhatian pada apa yang menjadi inti persoalan melalui asosiasi dan pengembangan imajinasi, menyelidiki setiap kemungkinan kesempatan yang terbuka dalam menyelesaikan masalah, memberikan kebebasan intelektual yang tak terbatas, memungkinkan melakukan penilaian terhadap gagasan-gagasan yang menjadi prioritas, memberikan pemahaman konsep yang lebih utuh karena dapat menciptakan kesan yang lebih kuat sehingga mudah dihafal. ${ }^{26}$ Jika demikian halnya, maka mind 
maps juga diharapkan dapat mengembangkan sikap kreatif dan perolehan hasil belajar yang lebih baik. Harapan seperti yang disebutkan di muka, menurut temuan penelitian ini adalah sesuai.

Aktivitas analogi yang didasarkan pada penstrukturan kembali kognitif karena masuknya informasi baru untuk mendapatkan pemahaman yang lebih baik, akan lebih lancar dengan mind maps. Mind maps sesungguhnya merupakan pemetaan informasi yang disimpan dalam pikiran, cara kerjanya didasarkan pada bagaimana otak mengatur dan menyimpan informasi. ${ }^{27}$ Proses yang demikian penting sebagai peristiwa yang mendahului elaborasi kognisi seseorang. Dalam teori pemrosesan informasi dijelaskan, peristiwa-peristiwa psikologi sebagai transformasi-transformasi informasi dari input ke output. Informasi mula-mula diterima oleh reseptor lalu masuk ke dalam registor penginderaan dan selanjutnya sebagian dari seluruh informasi dipindahkan ke memori, kemudian oleh generator respons diubah menjadi pola-pola perilaku yang membimbing efektorefektor menghasilkan serangkaian tindakan. ${ }^{28}$ Oleh Buzan pemrosesan informasi diaktualisasikan dalam bentuk mind maps berupa asosiasiasosiasi gagasan kreatif yang memicu potensi otak untuk dikembangkan secara maksimal. ${ }^{29}$ Di sinilah pentingnya mind maps digunakan sebagai alat bantu dalam membuat analogi-analogi pada kegiatan pembelajaran.

Kekuatan model synectics dan prasarana mind maps dalam hal mengembangkan kemampuan berpikir kreatif, penguasaan materi, dan sikap kreatif sangat memungkinkan karena keduanya memiliki cara kerja yang sama, yaitu sama-sama menggunakan asosiasi gagasan untuk menyelesaikan masalah. Cara kerja tersebut sesuai dengan paradigma pembelajaran konstruktivis. Menurut Piaget, pembelajaran konstruktivis adalah pembelajaran yang memungkinkan adanya pertukaran gagasangagasan untuk mengembangkan penalaran, memberikan kebebasan siswa untuk memiliki pendapat sendiri (mengemukakan, mempertahankan, dan merasa bertanggung jawab atasnya), dan kebebasan berpikir. ${ }^{30}$ Pembelajaran konstruktivis menekankan setiap siswa harus secara individu dapat menemukan, mengkonstruk, dan mentransfer informasi-informasi kompleks apabila mereka bermaksud menjadikan informasi tersebut untuk dimilikinya. ${ }^{31}$ Dari uraian tersebut, dapat dipahami bahwa pembelajaran konstruktivis menempatkan siswa sebagai pebelajar yang aktif (active learner) sehingga dinamakan pembelajaran yang terpusat pada siswa (student-centered instruction). Dalam pembelajaran yang berpusat pada siswa, peran guru adalah sebagai fasilitator yaitu membantu siswa menemukan fakta, konsep, atau prinsip bagi diri siswa sendiri. ${ }^{32}$ 
Berdasar beberapa hal yang telah dikemukakan di atas, tampaknya apa yang menjadi kekuatan pada model synectics dalam hal mengembangkan kreativitas semakin kuat setelah dipadu dengan mind maps. Hal tersebut didukung oleh temuan dalam penelitian ini.

\section{KESIMPULAN}

Sebagai kesimpulan penelitian yaitu penggunaan model pembelajaran synectics dipadu mind maps memberikan pengaruh yang signifikan terhadap kemampuan berpikir kreatif, sikap kreatif, dan penguasaan materi pelajaran pada siswa.

\section{SARAN}

Beberapa saran yang dapat dikemukakan berdasarkan hasil atau temuan penelitian ini, antara lain.

1. Jika tujuan pembelajaran yang dilakukan adalah untuk meningkatkan kemapuan berpikir kreatif, sikap kreatif, dan penguasaan materi biologi peserta didik, maka disarankan untuk menerapkan model pembelajaran ini.

2. Sedapat mungkin guru sains khususnya guru biologi memperhatikan kemampuan awal siswa dalam pemilihan model pembelajaran, agar tujuan pembelajaran dapat tercapai secara maksimal.

3. Agar model pembelajaran ini lebih berdaya guna, disarankan pada guru-guru biologi untuk memvariasikan model pembelajaran ini dengan model pembelajaran lainnya.

4. Berdasarkan pengalaman selama penelitian, disarankan agar dalam menerapkan model ini, materi yang akan dibelajarkan dirancang sendiri yaitu materi yang disertai dengan penjelasan-penjelasan analogis. Agar, siswa lebih mudah membuat analogi-analogi yang lain untuk mengembangkan imajinasi dan pemahaman akan konsep yang sedang dipelajarinya karena sudah ada contoh. Hal ini juga akan menghemat waktu pembelajaran yang sangat terbatas itu.

\section{CATATAN AKHIR:}

1. R. Gibson, Rethinking the Future: Rethinking Business, Principles, Competition, Control, Leadership, Market, and the World, diterjemahkan oleh Windi S. Brata dkk., Jakarta: PT. Gramedia, 2000, h. 59.

2. W. J. Raths dan Rothstein, Teaching for Thinking, New York: Teacher College Columbia University, 1986, h. 75.

3. T. L. Gie, Tehnik Berpikir Kreatif, Yogyakarta: PUBI dan Sabda Persada, 2003, h. 42 . 
4. M. Amien, Mengajarkan Ilmu Pengetahuan Alam (IPA) dengan Menggunakan Metode "Discovery" dan "Inquiry", Jakarta: Depdikbud, 1987, h. 72.

5. Liliasari, "Model Pembelajaran IPA Untuk Meningkatkan Keterampilan Berpikir Tingkat Tinggi Calon Guru sebagai Kecenderungan Baru pada Era Globalisasi" dalam Jurnal Pengajaran MIPA, 12 (1), 2001, h. 59.

6. Subiyanto, Strategi Belajar Mengajar Ilmu Pengetahuan Alam, Malang: IKIP Malang, 1990, h. 24. Lihat juga R.T. Joni, Peningkatan Mutu Pendidikan Melalui Pembelajaran Aktif dan Bermakna, Konsorsium Ilmu Pendidikan, Jakarta: Depdikbud Dikti, 1993, h. 48.

7. Ciputra, “Ajarkan Ilmu Kehidupan”, Jawa Pos, 4 Maret, 2007, h. 1.

8. M. Irtadji dkk., Pengajaran Kreatif di Jurusan Psikologi Pendidikan dan Bimbingan (PPB), Malang: Lembaga Penelitian, 1995, h. 69.

9. M. D. Gall, J. P. Gall dan W. R. Borg, Educational Research. $7^{\text {th }}$ Edition, Boston: Pearson Education, Inc., 2003, h. 402.

10. B. Joice dan M. Weil, Model of Teaching, $2^{\text {nd }}$ Edition, London: Printice-Hal, Inc., 1980, h. 162.

11. B. Joice dan M. Weil, Model of Teaching, h. 162. Lihat juga J. Brownoski, Synectics: Using Linking to Enhance Creativity, 1997, (http://webits 3.appstate.edu/apples/study/creativity/new_page_13.html, diakses 15 Pebruari 2005, h. 2.

12. D. Hudson, Prescription For Learning: Students Learn to Think About Thinking, Athens State University, 1998 (Online), (http://home.hiwaay.net-/kenth/ diane/column/98 to 01.html, diakses 28 Oktober 2004.

13. B. Joice dan M. Weil, Model of Teaching, h. 163. Lihat juga M. A. Gunter et al., Instructional A Model Approach, Boston: Allyn and Bacon, 1990, h. 137.

14. Appalachia State University web site, Synectics: Using Linking to Enhance Creativity, Retrieved February 15, from, (Online), (http://webits3.appstate.edu/apples/study/Creativity/new_page_13.htm, diakses 19 Pebruari 2005, 2003, h. 5.

15. J. Rakhmat, Psikologi Komunikasi, cetakan ke-22, Bandung: PT. Remaja Rosdakarya, 2005, h. 88.

16. A. Wahab, "Javanese Metaphor in Discourse Analysis", (Unpublished), Dissertation, University of Illinois at Champaign-Urbana, 1986, h. 189.

17. B. Joice dan M. Weil, Model of Teaching, h. 174.

18. M. Amien, Mengajarkan Ilmu Pengetahuan Alam (IPA) Dengan Menggunakan Metode "Discovery" dan "Inquiry", h. 128.

19. P. Ramasami, Students as Solid, Liquids, and Gases, Journal of Chemical Education, Vol. 2 (2): 141-147, 2002, h. 145.

20. J. L. Middleton, Student-Generated Analogies in Biology, The American Biology Teacher, 53 (1): 42 - 46, 1991, h. 45.

21. C. A. Coom dan M. Birken, Developing Analogical Thinking and Creativity in University Students, (online), 2003, http://www.aber.ac.uk/tfts/journalLarchive/biocoon.htm, diakses 17 Januari 2005, h. 3.

22. I Nyoman Sudana Degeng, Strategi Pembelajaran Mengorganisasi Isi dengan Model Elaborasi, Malang: IKIP Malang, 1997, h. 83.

23. M. A. Gunter et. al., Instructional A Model Approach, h. 135. 
24. S. Glynn et al., Teaching Science Concepts to Children: The Role of Analogies, (online), 1997, http://www.coe.uga.edu/edpsych/faculty/glynn/bios/ glynn_bio.html, diakses 20 Maret 2005, h. 2.

25. T. Buzan, Mind Maps at Work: Cara Cemerlang Menjadi Bintang di Tempat Kerja. terjemahan oleh Daniel Wijaya, 2005, cet. I, Jakarta: Gramedia, 2004, h. 6.

26. T. Buzan, Mind Maps at Work: Cara Cemerlang Menjadi Bintang di Tempat Kerja, h. 7. Lihat juga E. Bachman, Metode Belajar Berpikir Kritis dan Inovatif, cet. I, terjemahan oleh Bahrul Ulum, Jakarta: Prestasi Pustaka, 2005, h. 48. Lihat juga G. D. Dryden dan J. Vos, The Learning Revolution, cet.VII, terjemahan oleh Word ++ Translation Service, 2003, Bandung: KAIFA, 1999, h. 167.

27. Bachman, Metode Belajar Berpikir Kritis dan Inovatif, h. 48.

28. R. W. Dahar, Teori-teori Belajar, Jakarta: Depdikbud Direktorat Pendidikan Tinggi Proyek Pengembangan Lembaga Pendidikan Tenaga Kependidikan, 1988, h. 60. Lihat juga M.E.B. Gredler, Belajar dan Pembelajaran, cet. I, terjemahan oleh Munandir, Jakarta: Rajawali, 1991, h. 71.

29. T. Buzan, Mind Maps at Work: Cara Cemerlang Menjadi Bintang di Tempat Kerja, h. 9.

30. R. W. Dahar, Teori-teori Belajar, h. 193.

31. G. Leinhart, What Research on Learning, Tell us about in Teaching, in K. M. Cauley, F. Linder, J.H. McMillan (eds), Annual Editions: Educational Psychology of Human Thought (p. 182-213), New York: Cambridge University Press, 1992, h. 195.

32. Muhammad Nur, Pengembangan Model PBM IPA Berorientasi PKP untuk Meningkatkan Daya Nalar Siswa dalam Rangka Menyongsong Masyarakat IPTEK pada Pembangunan Jangka Panjang Tahap Kedua, Laporan Penelitian Hibah Bersaing 11/3 Perguruan Tinggi Tahun Anggaran 1995/1996, Surabaya IKIP Surabaya, 1995, h. 39.

\section{DAFTAR RUJUKAN}

Amien, M., Mengajarkan Ilmu Pengetahuan Alam (IPA) Dengan Menggunakan Metode "Discovery" dan "Inquiry", Jakarta: Depdikbud, 1987.

Appalachia State University web site, Synectics: Using Linking to Enhance Creativity, Retrieved February 15, 2003 from, (Online), (http://webits3.appstate.edu/ apples/study/Creativity/new_page_13.htm, diakses 19 Pebruari 2005.

Bachman, E., Metode Belajar Berpikir Kritis dan Inovatif, cetakan I, terjemahan oleh Bahrul Ulum, 2005, Jakarta: Prestasi Pustaka, tanpa tahun.

Brownoski, J., Synectics: Using Linking to Enhance Creativity. (http://webits 3.appstate.edu/apples/study/creativity/new_page_13.html, diakses 15 Pebruari 2005), 1997.

Buzan, T, Mind Maps at Work: Cara Cemerlang Menjadi Bintang di Tempat Kerja, cetakan I, terjemahan oleh Daniel Wijaya, 2005, Jakarta: Gramedia, 2004.

Ciputra, 4 Maret, 2007, Ajarkan Ilmu Kehidupan, Jawa Pos, h. 1.

Coom, C. A. dan Birken, M., Developing Analogical Thinking and Creativity in University Students, (online), (http://www.aber.ac.uk/tfts/journal-/archive/ biocoon.htm, diakses 17 Januari 2005.

Dahar, R. W., Teori-teori Belajar, Jakarta: Depdikbud Direktorat Pendidikan Tinggi Proyek Pengembangan Lembaga Pendidikan Tenaga Kependidikan, 1988. 
Degeng, I Nyoman Sudana, Strategi Pembelajaran Mengorganisasi Isi dengan Model Elaborasi, Malang: IKIP Malang, 1997.

Dryden, G. D. dan Vos, J., The Learning Revolution, cetakan VII, terjemahan oleh Word ++ Translation Service, 2003, Bandung: KAIFA, 1999.

Gall, M. D., Gall, J.P., dan Borg, W.R., Educational Research. $7^{\text {th }}$ Edition, Boston: Pearson Education, Inc, 2003.

Gibson, R., Rethinking the Future: Rethinking Business, Principles, Competition, Control, Leadership, Market, and the World, terjemahan oleh Windi S. Brata dkk, 2000, Jakarta: PT. Gramedia, tanpa tahun.

Gie, T. L., Tehnik Berpikir Kreatif, Yogyakarta: PUBI dan Sabda Persada, 2003.

Glynn, S., et al., Teaching Science Concepts to Children: The Role of Analogies, (online), (http://www.coe.uga.edu/edpsych/faculty/glynn/bios-/glynn_bio.html, diakses 20 Maret 2005, 1997.

Gredler, M.E.B., Belajar dan Pembelajaran, cetakan I, terjemahan oleh Munandir, 1991, Jakarta: Rajawali, tanpa tahun.

Gunter, M. A., et al., Instructional A Model Approach, Boston: Allyn and Bacon, 1990.

Hudson, D., Prescription For Learning: Students Learn to Think About Thinking. Athens State University, (Online), (http://home.hiwaay.net/kenth/diane/ column/98 to 01.html, diakses 28 Oktober 2004, 1998.

Irtadji, M., dkk., Pengajaran Kreatif di Jurusan Psikologi Pendidikan dan Bimbingan $(P P B)$, Malang: Lembaga Penelitian, 1995.

Joice, B. dan Weil, M., Model of Teaching, 2nd Edition, London: Printice-Hal, Inc., 1980.

Joni, R. T., Peningkatan Mutu Pendidikan Melalui Pembelajaran Aktif dan Bermakna, Konsorsium Ilmu Pendidikan, Jakarta: Depdikbud Dikti, 1993.

Liliasari, Model Pembelajaran IPA untuk Meningkatkan Keterampilan Berpikir Tingkat Tinggi Calon Guru Sebagai Kecenderungan Baru pada Era Globalisasi, Jurnal Pengajaran MIPA, 12 (1): 54 - 66, 2001.

Middleton, J. L., Student-Generated Analogies in Biology, The American Biology Teacher, 53 (1): 42-46, 1991.

Nur, Muhammad, Pengembangan Model PBM IPA Berorientasi PKP untuk Meningkatkan Daya Nalar Siswa dalam Rangka Menyongsong Masyarakat IPTEK Pada Pembangunan Jangka Panjang Tahap Kedua, Laporan Penelitian Hibah Bersaing 11/3 Perguruan Tinggi Tahun Anggaran 1995/1996, Surabaya IKIP Surabaya, 1995.

Ramasami, P., Students as Solid, Liquids, and Gases, Journal of Chemical Education, Vol. 2 (2): 141-147, 2002.

Raths, W. J., dan Rothstein, Teaching for Thinking, New York: Teacher College Columbia University, 1986.

Subiyanto, Strategi Belajar Mengajar Ilmu Pengetahuan Alam, Malang: IKIP Malang, 1990. 